\title{
New approaches to vaccines for endemic and pandemic diseases of Africa with particular focus on building local competencies in Cameroon.
}

\author{
Vincent PK Titanji, PhD; \\ (PhD; FCAS; FAAS; TWAS) \\ Emeritus Professor, \\ Biotechnology Unit, University of Buea
}

Email: vpk.titanji@,yahoo.com

\begin{abstract}
Vaccines have been recognized as major and effective tools for the control and eventual elimination of infectious diseases and cancer. This brief review examines vaccine classification and development pipeline as well as recent innovations driving the vaccine development process. Using COVID-19 as an example recent innovation in vaccine development are highlighted. The review ends with a call for intensified efforts to build vaccine production capacity in Cameroon and other other African countries.
\end{abstract}

\section{Resumé}

Les vaccins ont été reconnus comme des outils majeurs et efficaces pour le contrôle et l'élimination éventuelle des maladies infectieuses et du cancer. Cette brève revue examine la classification et le pipeline de développement de vaccins ainsi que les innovations récentes à l'origine du processus de développement de vaccins. En utilisant COVID-19 comme exemple, les innovations récentes dans le

Received: 09/06/2021
Accepted: 23/07/2021
DOI: https://dx.doi.org/10.4314/jcas.v17i1.6
C The Authors. This work is published under the Creative Commons Attribution 4.0 International Licence. 
développement de vaccins sont mises en évidence. La revue se termine par un appel à intensifier les efforts pour renforcer les capacités de production de vaccins au Cameroun et dans d'autres pays africains.

\section{Introduction}

Vaccines have emerged as major tools for the control of infectious diseases and cancer (Plotkin,2003;Hussein,2015) Currently vaccines are known to save at least 2-3 million lives annually worldwide. The eradication of small pox in 1980 and the recent elimination of polio in 2020 are monumental landmark achievements attributed to vaccines in the history of Medicine. (Razum et al, 2019).

However, endemic diseases such as malaria, HIV/ AIDS and cancer still do not have effective and safe vaccines. Through concerted international efforts across the globe vaccines against the COVID-19 pandemic, which were in the advanced stages of development in 2020 have been approved are in the process of being deployed as from January 2021 (WHO, 2021). Predictably, the countries that developed the COVID-19 vaccines (China, United Kingdom, Russia and United States of America) are being served first followed by the rich countries of Europe with the vast majority of developing countries, waiting impatiently to receive the COVID-19 vaccines through bilateral agreements and/or through the WHO/COVAX platforms. (WHO, 2021).

By all accounts the development of COVID-19 vaccines took about a year as compared to the 10 or more years that it usually takes to develop a vaccine. These extraordinary advances have been attributed, not only to the strides made in the science of vaccinology, but also to the mobilisation of resources and the availability in the public domain of crucial scientific information, notably the genome sequence of SARS-CoV-2 the causative agent of COVID-19 by Chinese scientists (Wang, et al ; 2020) Advances in Recombinant DNA technology, Immunology and Bioinformatics have considerably accelerated vaccine development in advanced countries, while the developing countries are still lagging behind in these domains. The need to build capacity to design, manufacture, test and deploy vaccines is a priority in African countries.

This paper briefly examines some new approaches to vaccine development and suggests some key points in the adaptation of these approaches to resource limited countries, including Cameroon. Thus, sections that follow will briefly cover the classification of vaccines, vaccine development pipeline, new approaches to vaccine development, COVID-19 Vaccines, a call for capacity building for vaccine development and production in Africa. Vaccine Classification. Vaccines can be classified based on criteria such as structure/ platform, function, route of administration etc. For the purpose of this article, we will focus on classification based on biological/biochemical structure and platform (Kaur and Gupta,2020) Following this system, vaccines can be classified into two main categories: whole pathogen vaccines comprising of live attenuated vaccines inactivated vaccines and sub-unit vaccines composed of isolated components (molecules) from the pathogen. The sub-unit vaccines are composed of proteins, nucleic acids (DNA and RNA), complex carbohydrates or combinations of these (Table 1) 
Table 1. Classification of Vaccines according to platform

\begin{tabular}{|l|l|l|}
\hline Type & Platforms & Examples of Vaccines \\
\hline 1.Whole pathogen & 1.1 Live attenuated Vaccine & 1.1Polio, Yellow Fever \\
Vaccines & 1.2 Killed Inactivated Vaccine & 1.2 BCG \\
\hline 2. Sub-Unit Vaccine & 2.1 Protein Antigen & 2.1 Hepatitis B Surface antigen \\
& 2.2Carbohydrate Antigen & 2.2 Meningitis Vaccine r \\
& 2.3 DNA vectored vaccine & $2.3 \quad$ Oxford/Astra/ Zaneca \\
& COVID-19 Vaccine r mRNA & 2.4 Pfizer/ BioNtech COVID-19 \\
& & Vaccine; Moderna COVID-19 \\
& Vaccine \\
\hline
\end{tabular}

Each Type of vaccine has both its advantages and limitations or disadvantages as discussed extensively by (Kaur and Gupta, 2020). During the past two decades the tendency has been to move from whole pathogen vaccines to sub-unit vaccines, because the latter are easier to manufacture and standardize than the former. In this regard a lot of attention has been placed on protein sub-unit vaccines, which can be cloned, expressed and purified to obtain sufficient quantities for large scale distribution. The entire process can be sophisticated requiring wellequipped laboratories and state- of- the- art factories.

In the early 1990's it was shown that direct injection of DNA coding for an antigen into the skeletal muscles of could provoke an immune response to the antigen concerned (Wang, et al, 2014). Similar experiments by Wolf et al (1990) also showed that the messenger RNA transcript of an antigen injected into the skeletal muscle could induce both protective humoral and cellular immune responses in the host. These seminal observations laid the foundations for nucleic acid sub-unit vaccines (Pardi et al; 2018)

Although a lot of work has been done on DNA vaccines in experimental animals there have been objections on ethical grounds for the use of DNA vaccines in humans (KAUR and Gupta,2020). However, these objections are being circumvented by engineering the genes coding for the relevant protein antigen into a harmless virus (eg Chimpanzee Adenovirus) and using the recombinant construct as the vaccine (Sayedamed et al 2020)

History will retain that in the year 2020, the first mRNA vaccines were tested on a large scale in humans and shown to be both efficacious and safe, thereby opening the way for their use in 2021 to stem off the devastation caused by the COVID19 pandemic (WHO, 2021; CDC ;2021).

Thus, all three biomolecules involved in the Molecular Biology Dogma, which states that genetic information flows from DNA through RNA to proteins ie:

(DNA- $\rightarrow$ RNA- $\rightarrow$ Proteins)

can be employed as sub-unit vaccines. The detailed mechanisms on how sub-unit vaccines work has been reviewed extensively (Kaur and Gupta, 2020; Tahir ul Qamar et al, 2020) and fall out of the scope of this mini review.

\section{The Vaccine Development Pipeline.}

Vaccine/ drug development proceeds in five distinct stages namely, Discovery; Non-Clinical Studies; Clinical Trials, Registration; Marketing and Pharmaco-vigilance (WHO, 2001). 
(Table2) Drug /Vaccine Discovery pipeline

\begin{tabular}{|l|l|l|l|}
\hline STAGE & NAME & QUALITY STANDARDS & $\begin{array}{l}\text { LEGAL } \\
\text { STATUS }\end{array}$ \\
\hline I & DISCOVERY & Quality Standards in Basic Biomedical Research (QSBR) & Non-regulated \\
\hline II & $\begin{array}{l}\text { NON-CLINICAL } \\
\text { STUDIES }\end{array}$ & $\begin{array}{l}\text { Good Laboratory Practice (GLP) } \\
\text { Good Manufacturing Practice (GMP) in later stages }\end{array}$ & Regulated \\
\hline III & CLINICAL & $\begin{array}{l}\text { Good Clinical Practice (GCP) } \\
\text { Good manufacturing Practice (GMP) }\end{array}$ & Regulated \\
\hline IV & REGISTRATION & $\begin{array}{l}\text { The Regulatory authority reviews data from the stage II before } \\
\text { authorising stage II; data from stage III before authorising stage IV }\end{array}$ & Regulated \\
\hline V & $\begin{array}{l}\text { DISTRIBUTION/ } \\
\text { MARKETING/ } \\
\text { PHARMACO- } \\
\text { VIGILANCE }\end{array}$ & Good Clinical Practice (GCP) & \\
\hline
\end{tabular}

The first two stages are not regulated, whilst the remaining three are. However, Good Practice principles (QSBMS; GLP, GCP, GMP) apply to the respective stages. Normally this process takes about 10 years, but in extreme cases this can be accelerated without compromising on safety and efficacy.

COVID-19 Vaccines: More than 100 COVID19 vaccines were under development in (November 2020 when CAS held its Symposium) with perhaps a dozen of them in advanced stage III clinical trials. COVID 19 vaccines fall in the four of the five categories described above (Table
1). In mid- 2020, the Chinese Russian governments announced the registration of COVID-19 vaccines, which were initially not available outside the respective countries, but which have subsequently been made available to other countries. The US authorised the use of three vaccines in less than three months, namely the Pfizer BioNTech, Moderna and Johnson \& Johnson COVID-19 Vaccines. The UK developed the Oxford/Astra Zeneca vaccine shortly after the registration of the Pfizer and Moderna vaccines (Table 3 )

Table 3. World Health Organization (WHO)-approved COVID-19 vaccines

\begin{tabular}{|c|c|c|c|}
\hline No. & Name & $\begin{array}{l}\text { Description/ } \\
\text { Platform }\end{array}$ & Country of Origin \\
\hline 1. & $\begin{array}{l}\text { Moderna } \\
\text { mRNA-1273 }\end{array}$ & Messenger RNA & USA \\
\hline 2. & $\begin{array}{l}\text { Pfeizer BioNtech } \\
\text { BNT162B2 }\end{array}$ & Messenger RNA & USA with Germany \\
\hline 3. & $\begin{array}{l}\text { Janssen (Johnson } \\
\text { \& Johnson) } \\
\text { Ad26CoV2.S }\end{array}$ & $\begin{array}{l}\text { Adenovirus } \\
\text { (non-replicating viral vector) }\end{array}$ & USA \\
\hline 4. & $\begin{array}{l}\text { Oxford/ ASTRA/ } \\
\text { Zeneca } \\
\text { AZD1222 }\end{array}$ & Non-replicating viral vector & UK with Sweden \\
\hline 5. & $\begin{array}{l}\text { Serum Institute of India } \\
\text { Covisheld (Astra Zeneca Formulation) }\end{array}$ & Non-replicating Viral Vector & UK/India \\
\hline 6 & $\begin{array}{l}\text { Sinopharm (Beijing) } \\
\text { BB1Bp-CorV }\end{array}$ & Inactivated virus & China \\
\hline 7. & $\begin{array}{l}\text { Sinovac } \\
\text { (Corona Vac) }\end{array}$ & Inactivated virus & China \\
\hline
\end{tabular}

Source: https://covid19.trackvaccine.org/agency/who/. Accessed 6 August 2021 
As pointed out above, the rapid development of these vaccines and many others in the pipeline has been aided by the publication of SARS-CoV2 genome by the Chinese Government barely 2 months after the emergence of the COVID-19 pandemic. The main challenges faced by developing countries is, not only the eventual availability of the vaccines, but also vaccine hesitancy fuelled by social media disinformation (Dinga et al, 2021). Solutions to these challenges include building indigenous capacity in the developing countries to manufacture and verify the vaccines for safety and efficacy as well as strengthening international collaboration to facilitate access to available vaccines. Obviously, the timing of these actions will depend on the local context in each country, which is why we cannot be prescriptive. This not withstanding we cannot simply set aside the experiences of other countries but examine them to avoid pitfalls and learn from good practices.

\section{Innovative Vaccine design and delivery:} Innovative design approaches include the use reverse vaccinology, targeting multiple rather than one target, use of nano-particles to deliver vaccines; creating therapeutic vaccines and ring vaccination. Brief explanations of these approaches follow in the next sections where references are given to more elaborate treatments.

Reverse vaccinology as the name implies shortcircuits the traditional vaccine discovery process by starting with the whole genome sequence to predict potential vaccine candidates followed by molecular cloning, expression, purification and immunogenicity testing (Rappuoli;2000; Tahir ul Qamar,2020). The crucial step of vaccine discovery starts not with the pathogen as is traditionally done but with genome information which is analysed in silico using a variety of software. The new disciplines of Bioinformatics, Computational Biology facilitate candidate vaccine discovery and characterization once the genome information is available (Ong et al,2021)

From Univariate to multivariate sub-unit vaccines. A vaccine candidate target can be defined as structural unit in the pathogen, which when blocked by an immune effector mechanism neutralises the pathogen or the pathogens pathogenic effects. Thus, a vaccine target can be a protein, a complex polysaccharide, lipoprotein, or an epitope (i.e., a small part of the larger antigen capable of eliciting an immune response).

According to a what I have described as the Hill of Achilles Hypothesis, it was thought that in the pathogen there existed a single target, a weak spot, crucial for the pathogen's survival, which if blocked would compromise and eventually eliminate the pathogen. As indicated elsewhere (Titanji et al,2017 and 2020) this hypothesis may work well for simple organisms with a well conserved vaccine target, but it may not be valid for parasites which typically have multiple stages in their life cycles or for some viruses which mutate frequently. Vaccine designers are turning more often to multivariate rather than univariate vaccines to cope with the challenges of frequent mutations and diversity of host responses to specific antigen (De Souza and Doolan, 2016; Titanji et al, 2017).

The use of nanoparticles in vaccine design.

Another significant innovation in the field of vaccinology is the use of nanoparticles for vaccine packaging and delivery (Kheirollhpour, et al,2020). Nanoparticles are materials with the dimensions of 1-100 nanometers, one nano meter being equal to one -billionth of a meter. These particles, which are composed of a few hundred atoms have unique physico-chemical properties and have found applications in wide range of fields including engineering, pharmaceutical industry, new materials and vaccinology. 
The designers of the successful mRNA vaccines Pfeizer/BioNTech and Moderna have taken advantage of nanotechnology and their successes are likely to lead other vaccine designers to use the same approaches.

\section{Therapeutic vacines.}

The concept of therapeutic vaccines once viewed with skepticism is now gaining traction thanks to advances in vaccine science (Ngu et al,1979; Melero,2014). While classical vaccines are preventive in that they prime and prepare the host to fight the pathogen in a subsequent infection; therapeutic vaccines are curative and act by stimulating the host immune system to attack on ongoing disease like a drug. The concept of therapeutic vaccination should not be confused with the passive transfer of acquired immunity, which is the use of convalescent plasma for the treatment of COVID-19. Whereas pooled convalescent plasma from one group of donors can be used on a different group of patients, a therapeutic vaccine is individualized ie developed for each patient's leucocytes in vitro and reinjected into the same patient. In this way the therapeutic vaccine is expected to short-circuit the elaborate vaccine development pipeline described above. However, it may be challenging for mass treatments in resource poor environments with inadequate supportive infrastructure and personnel.

\section{Ring Vaccination.}

To stop the spread of COVID19 pandemic it has been recommended that at least $70 \%$ of the population should be vaccinated in order to attain herd immunity which will eventually eliminate the virus from circulation. However, this is not feasible in developing countries of Africa where there is a paucity of vaccines and hesitancy is effectively stalling vaccine uptake (Dinga et al, 2020). In such circumstances, ring vaccination could be envisaged.
Ring vaccination is indicated in situations where the infection is localised and deadly. The patients are isolated and any person likely to have come in contact with a patient is quarantined and vaccinated. In this way the infection is localised and can be contained. This was the strategy used to contain the recent Ebola outbreak in DR Congo. Ring vaccination, however, requires efficient and wide scale testing, patient-tracing capacity and greater acceptance of vaccines by the target population (Deen and von Seiden,2018).

The Urgent Need to develop and Produce required Vaccines.

The ongoing COVID19 has highlighted the need for developing countries in general and African countries in particular to set up and produce as a priority the vaccines the need to fight the COVID pandemic, and ultimately the lifesaving vaccines such as are mentioned in the WHO Expanded Program for Immunization (EPI). The vaccine development process is highly complicated and various countries of Africa will have different needs should they wish to set up for vaccine production. Currently a few countries (South Africa, Senegal, Morocco, Nigeria, Kenya have the capacity to produce vaccines (Otto,2021). The current thinking is favour of a pan-African approach facilitated by the African Union to set up COVID vaccine production facilities in Africa with the collaboration of international overseas partners. South Africa is reported to be in negotiations to produce the Oxford/AstraZeneca Covid vaccine locally, while Morocco is reported to poised to produce the Chinese Sinopharm COVID 19 vaccine in the respective African counties. While such initiatives might be appropriate as a short-term measure to curb the ongoing pandemic, they do not absolve African countries collectively and individually from building the capacity to produce essential vaccines and drugs in Africa. 
The Cameroon Academy of Sciences has made recommendations to the Government on the need to strengthen laboratories in the country in the crucial domains of drug and vaccine production.

Conclusion. There is an urgent need to develop the capacity to carry out all the stages of the vaccine pipeline locally. The Cameroon Academy of Sciences has recommended the creation of Levels 3 and 4 containment laboratories and training of personnel to work safely with infectious agents such as SARS-CoV-2 as well as to verify the safety and efficacy of imported vaccines and drugs.

Acknowledgements. I thank the university of Buea and the Cameroon Christian University Institute for institutional support. *An earlier version of this article was presented as a PowerPoint Lecture at the CAS Week of Science for National Development held in Yaoundé on the $6^{\text {th }}-8^{\text {th }}$ October 2020

\section{References}

African CDC partnership for COVID Vaccine www.afrcacdc.org accessed 11/08/2021.

Center for Disease Control and Prevention, COVID-19. www.cdc.gov

.De Souza, KP and Doolan, DL (2016) Immunomics: a $21^{\text {st }}$ Century approach to vaccine development for complex pathogens. Parasitology,43(2):236-244 doi: https:// $\underline{10.1017 / \mathrm{s} 00311820150001079}$

Deen, J and von Seiden, L (The case for ring vaccinations with special consideration of cholera oral vaccines. Human Vaccines \& Immunotherapeutics ,14(8):2069-2074. Doi: $10.1080 / 21645515.2018 .1462068$

Dinga JN; Sinder LK; Titanji VPK.(2021). Assessment of vaccine hesitancy to a COVID-
19 vaccine in Cameroonian adults and its global implication. Vaccines, 9,175. https://doi.org/ 10.3390/vaccines $9020175 / 08 / 2021$

Forni, G and Mantovan, A.(2021). COVID-19 Vaccines where we stand and Challenges ahead. Cell death and Differentiation, 28:626-639. doi: https://doi.org/10.1038/s41418-020-00720-9

Hussein IH; Chams,N;Chams S; Sayegh SE; Badran R; Raad M;Gerges-Geagea,A;Leone A; Jurjus A. (2015) Vaccines through the centuries : Major Corner stones of Public Health.

Frontiers in Public Health,3:269. Doi:10.3389/ fpubh.2015.00269

Kaur, SP and Gupta, V. (2020). COVID-19 Vaccine: A comprehensive status report.Virus Research,288:198114 doi: https://doi.org/ $\underline{10.1016 / j . v i r u s r e s .2020 .198114}$

Kheirollhpour M; Mehrabi, M; Dounighi NM; Mohammadi M; Masoudi A .(2020). Nanoparticles and Vaccine Development. Pharmaceutical Nanotechnology,8(1) doi:10.2174/2211738507666191024162042

Melero,I;Gudermac G; Gerritsen W; Huber C; Parmiani, G; Scholl S; Thatcher N; Wagstaff J; Zelinski C; Faulkner,I; Mellsted, H (2014). Therapeutic vaccines for cancer: an overview of clinical trails. Nature Reviews Clinical Oncology, 11:509-524. Doi: 10.1038/nrclinonc.2014.111

Ngu,VA; Titanji,VPK; Muna D; Nyoth J; Lekeuagni,C (1981) Clinical Experience with autobiotherapy of malignant tumor disease: a preliminary report. Journal of the National Medical Association (USA), vol 73 (10):927-937

Ong, E; Wong, MU; Huffman, A; He, Y. (2021). COVID -19 coronavirus vaccine design using reverse vaccinology and machine learning. doi: https://doi.org/10.1101/2020.03.20.000141 
Otto, B (2021) What is Africa's vaccine production capacity? www.afro.who.int/news

Pardi N; Parkhouse K; Kirkpatrick E; McMahon,M; Zost SJ; Mui BL; Tam YK; Karik K;Barbosa CJ;Madden TD;Hope, MJ; Krammer, F; Hensley,SE; Weissman,D .(2018). Nucleosidemodified mRNA immunization elicits influenza virus. Nature Communications,9:3361. Doi:10.1038/s41467-018-05482-0

Plotkin SA. (2003). Vaccines, Vaccination, Vaccinology. The Journal of Infectious Diseases, 187:1349-1359

14.Rappuoli.(2000) Reverse Vaccinology. Current opinion in Microbiology, 3:445-450

15. Razum o; Sridhar,D; Jahn, A; Zaidi,S;Ooms G; Mulle O .(2019). Polio from eradication to systematic, sustained control. British Medical Journal,4:e001633 .doi:10.1136/bmjgh-2019001633

Sayedamed EE; Elkashi, A Alhashimi m; Sambhara S;Mittal,SK.(2020 )Adenoviral Vectorbased Vaccine Platforms for Developing the next generation of influenza vaccines. Vaccines (Basel) 8(4):574. Doi:10.3390/Vaccines8040574.

Tahir ul Qamar,M; Shahidz,F; Aslam,S; Asfaq,UA; Aslam,S; Fatima,I; Fareed,MM; Zohaib,A; Ling-Ling, Chen. (2020). Reverse Vaccinology assisted designing of multiepitopebased subunit vaccine against SARS-CoV-2. Infectious Disease of Poverty,9: 132. doi: https:/ Ldoi.org/10.1186/s40249-020-00752-w

Titanji,VPK; Dinga, J.N; \& Nyasa, R.B.(2017).A rational approach for predicting the minimum composition of anti-parasite sub-unit vaccines:
A multiple target vaccine hypothesis, Journal of the Cameroon Academy of Sciences,14(1): 3 10. DOI:https://doi.org/10.4314/jcasv14i1.1

Wang L;Mitchell PK; Calle PP; Bartlett SL;McAloose D; Killian ML; Yuan F; Fang Y; Goodman LB; Fredrickson R; Elvinger F: Terio K; Franzen K; Stuber T; Diel DG; Torchetti MK (2020). Complete genome sequence of SARSCoV-2 in a tiger form at a U.S. zoological collection. Microbiology Resource Announcements 9:e00468-20. https://doi.org/ $\underline{10.1128 / M R A .00468-20}$

Wang,S and Lu, S (2014) DNA immunization. Current Protocols in Microbiology,31: 18.3.118.3 .24 . d o i. $10: 10.1002 /$ 9780471729259.mc1803s31

WHO (2001) (a) Quality Standards for Biomedical Research/PRD/QSBR/01.1

WHO (2001) (b) Good Laboratory Practice Training Manual.www.who.in/tdr

WHO (2001) (c) Guidelines on clinical evaluation of vaccines: regulatory expectations

WHO Frameworks for technology transfer www.who.int accessed 11/08/2021

WHO (2021) Report of the independent allocation of vaccines group on the allocation of COVAX-facility secured vaccines, 29July 2021. www.who.int/publications/m/item.

WHO approved Covid 19 Vaccines. https// covid19.trackvaccines.org/agency/who accessed 11/08/2021.

Wolff JA; Malone RW,Williams ,P;Chong,W; Ascadi,G; Jani A;Felgner, L P (1990) Science (1990) Direct gene transfer into mouse muscle in vivo.Science,247(4949):1465-1468 
Xu W; Su S; Jiang S; (2021). Ring vaccination of COVID-19 vaccines in medium and high-risk areas of countries with low incidence of SARS COV-2 Infection. Clinical and Translational Medicine 2021; e331.https://doi.org/10.1002/ ctm2.331.

Titanji, VPK. 2020. A new paradigm for the development of anti-parasitic vaccines: The discovery of UB05-based vaccines for malaria. BOOK of Abstracts. CAS week of Science in the service of national development held in Yaoundé on the $6^{\text {th }}$ to the $8^{\text {th }}$ October, 2020, P16. www.casciences.org 